\title{
RELEVANSI SUSASTRA HINDU DENGAN PENDIDIKAN KARAKTER
}

\author{
Oleh: I Made Arsa Wiguna ${ }^{1}$
}

\begin{abstract}
This paper aims to present the idea of the relevance of Hindu's literature with character education which is currently being encouraged to raised up back in the learning process. Education in general and religious education is basically aimed at forming good character. But today there's a phenomenon of moral degradation among teenagers, although there's also the others which has a good moral and character. One of the effort that can be choose to support character education is by reviving religious literature. Literature in Indonesia has existed since the entry of Hindu's influence to the archipelago. Even in the range of $X$ century, King Dharmawangsa Teguh initiated a project known as "mangjawaken byasamata" or to translating to the Java language the teachings of Bhagavan Vyasa. Hindu's literature nowadays is still well preserved especially in Bali. Bali as the savior of Hindu's literature and not only protecting literary works but also developed forms of other literary works. Hindu's literature to support the efforts of the character education is Sarasamuccaya and Canakya Nitisastra. The values in it, is still relevant in today's life and a valuable asset for character education. Its need to practice and accustom these teachings so that the purpose of education to humanize humans, and to realize humans could be achieved.
\end{abstract}

Keywords: Relevance Hindu's Literature, Character Education

\begin{abstract}
Abstrak
Tulisan ini bertujuan untuk menyampaikan gagasan mengenai relevansi susastra Hindu dengan pendidikan karakter yang dewasa ini sedang didorong untuk dumunculkan kembali dalam proses pembelajaran. Pendidikan secara umum maupun pendidikan agama pada dasarnya bertujuan untuk membentuk karakter yang baik. Namun dewasa ini muncul fenomena degradasi moral di kalangan remaja, meskipun tidak sedikit di antaranya yang masih memiliki moral dan budi pekerti yang luhur. Salah satu upaya yang dapat dilakukan untuk mendukung pendidikan karakter yakni dengan menghidupkan kembali susastra agama. Kesusastraan di Indonesia sudah ada sejak masuknya pegaruh Hindu ke Nusantara. Bahkan pada kisaran abad ke X, Raja Dharmawangsa Teguh menggagas sebuah proyek yang yang dikenal dengan "mangjawaken byasamata" atau membhasa jawakan ajaran Bhagawan Byasa. Hingga kini kesusastraan Hindu masih tetap terpelihara dengan baik terlebih di Bali. Bali sebagai penyelamat kesusastraan Hindu tidak hanya melindungi karya sastra tersebut namun juga mengembangkan bentuk-bentuk karya sastra lainnya. Kesusastraan Hindu yang dapat mendukung upaya pendidikan karakter yakni Sarasamuccaya dan Canakya Nitisastra. Nilai-nilai di dalamnya, masih sangat relevan di kehidupan saat ini merupakan aset yang sangat berharga bagi pendidikan karakter. Perlu usaha untuk mengamalkan dan mentradisikan ajaran-ajaran tersebut sehingga tujuan pendidikan untuk memanusiakan manusia, serta mewujudkan manusia yang berbudi pekerti luhur dapat tercapai.
\end{abstract}

\section{Kata Kunci: Relevansi Susastra Hindu, Pendidikan Karakter}

${ }^{1}$ I Made Arsa Wiguna, Dosen Fakultas Dharma Acarya IHDN Denpasar 


\section{PENDAHULUAN}

Pendidikan merupakan usaha sadar dan terencana untuk memanusiakan manusia, atau usaha pendidik untuk membimbing secara sadar peserta didik dengan mengarahkan sikap, prilaku, mental dan spiritual mereka menjadi manusia yang berbudi pekerti luhur. Pendidikan tidak semata-mata proses trasmisi kebudayaan, namun lebih daripada itu adalah untuk membentuk pribadi anak agar memiliki moral dan budi pekerti luhur.Anak dengan kepribadian mulia tentu menjadi idaman semua keluarga, oleh karenaitu pendidikan memiliki peran vital dalam pertumbuhan dan perkembangan anak. Langgulung (dalam Jalaluddin, 2012: 188) menyatakan bahwa pendidikan mencakup dua kepentingan utama, yaitu pengembangan potensi individu dan pewarisan nilai-nilai budaya. Kedua hal ini berkaitan erat dengan pandangan hidup suatu masyarakat atau bangsa itu masing-masing. Dapat disimpulkan bahwa sesederhana apapun pendidikan tersebut pasti mengandung unsur ataupun karakteristik atau falsafah hidup bangsa yang bersangkutan.

Menurut Jalaluddin (2012: 192) bangsa Indonesia dengan filsafat dan pandangan hidupnya yakni Pancasila menjadi tujuan sistem pendidikan nasional. Dengan kata lain, sistem pendidikan nasional disusun atas dasar filsafat pendidikan Pancasila. Pendidikan sesuai dengan fungsinya yakni mengembangkan potensi individu, dan juga mentrasnmisi nilainilai budaya, oleh sebab itu pendidikan akan berkaitan erat dengan pembentukan kepribadian yang luhur. Setidak-tidaknya kepribadian dapat dilihat dari empat aspek muatannya yakni: 1) Aspek personalia yaitu kepribadian dilihat dari pola tingkah laku lahir dan batin yang dimiliki seseorang, 2) Aspek individualitas yakni karakteristik atau sifat-sifat khas yang dimiliki seseorang, 3) Aspek mentalitas sebagai perbedaan yang berkaitan dengan cara berpikir, 4) Aspek identitas yaitu kecenderungan seseorang untuk mempertahankan sikap dirinya dari pengaruh luar.
Berbicara masalah pendidikan di tanah air, nampaknya belum menunjukkan hasil yang memuaskan. Rendahnya kualitas sumber daya manusia di tanah air menjadi indikator lemahnya sistem pendidikan yang ada. Pemerintah terus berupaya untuk mengoptimalkan pembangunan di bidang pendidikan meskipun banyak menemui kendala. Pendidikan karakter menjadi salah satu langkah strategis yang diambil pemerintah dalam upaya memecahlan persoalan-persoalan terkait runyamnya pendidikan di tanah air. Cholisisin dalam sebuah makahlahnya berjudul "Peran Guru PKn dalam Pendidikan Karakter" menyatakan bahwa adanya kebijakan nasional dalam hal pembangunan karakter bangsa dilatarbelakangi atau didasarkan oleh permasalahan yang sedang dihadapi bangsa kita saat ini yakni: 1) Disorientasi dan belum dihayatinya nilai-nilai Pancasila sebagai filososi dan ideologi bangsa,

2) Keterbatasan perangkat kebijakan terpadu dalam mewujudkan nilai-nilai esensi Pancasila,

3) Bergesernya nilai-nilai etika dalam kehidupan berbangsa dan bernegara, 4) Memudarnya kesadaran terhadap nilai-nilai budaya bangsa, 5)Ancaman diintegrasi bangsa, 6) Melemahnya kemandirian bangsa.

Swami Sathya Narayana (dalam Titib, 2003: 19) dengan tegas menyatakan bahwa tujuan dari pendidikan secara umum maupun pendidikan agama adalah untuk pembentukan karakter yang baik (character building), selengkapnya sebagaiberikut:

"tujuan pengetahuan adalah kearifan, tujuan peradaban adalah kesempurnaan, tujuan kebijaksanaan adalah kebebasan, dan tujuan pendidikan adalah karakter yang baik".

Dewasa ini ada kecenderungan menurunnya moralitas remaja sebagai akibat ketidaksiapan dalam hal menangkal pengaruh arus modernisasi dan globalisasi. Seperti yang diaungkapkan Lickona ada tren merosotnya moral remaja, meskipun tidak sedikt di antaranya yang masih memiliki moral dan budi 
pekerti luhur. (Lickona, 2013: 15-25) merinci ada sepuluh indikator bobroknya moral remaja yakni : 1) Kekerasan dan vandalisme, 2) Pencurian, 3) kecurangan dan ketidak jujuran, 4) Tidak menghormati figur otoritas yang terjadi di hampir sebagian besar sekolah maupun perhuruan tinggi, 5) Kekejaman dan kekerasan oleh teman sebaya yang sudah menjadi ancaman serius dalam kehidupan sosial siswa di sekolah, 6) Kefanatikan yang akhirnya menghilangkan semangat toleransi di kalangan remaja, 7) Bahasa yang kasar, 8) Pelecehan dan perkembangan seksual yang terlalu cepat, 9) Meningkatnyasifat mementingkan diri sendiri dan menurunnya tanggung jawab sebagai warga negara, 10) Perilaku merusak diri. Dihadapkan pada persoalan-persoalan semacam itu, negara-negara di seluruh dunia kembali menoleh pada sistem pendidikan mereka. Kekhawatiran bahwa mengajarkan nilai dan moral dapat menggangu pluralisme dan mengecewakan beberapa kalangan, seperti yang dirasakan beberapa tahun sebelumnya kini seolah menjadi sebuah kebenaran yang terbukti dengan sendirinya. Tidak membekali generasi muda dengan pemahaman moral adalah sebuah kegagalan etis serius dari masyarakat.

Pendidikan sebagai proses transmisi budaya tidak dapat dipisahkan dari falsafah bangsa ini dan juga tentunya warisan-warisan budaya yang telah ada tidak dapat dikesampingkan. Sebagai bangsa dengan beragam kebudayaan, Indonesia memiliki peluang besar dalam menanamkan pendidikan karakter. Dengan menggali kearifan lokal, niscaya tujuan pendidikan dapat diwujudkan bersama. Nenek moyang kita telah mewarisi beragam kebudayaan mulai dari bahasa, pengetahuan, teknologi, sistem organisasi kemasyarakatan, sistem mata pencaharian atau ekonomi, religi, dan kesenian. Salah satunya adalah dalam bidang kesusastraan, baik dalam bentuk lisan maupun tertulis. Kesusastraan dilihat dari fungsinya memiliki lima macam fungsi yakni: 1) Fungsi rekreatif, 2)Fungsi religius, 3) Fungsi didaktif (pendidikan), 4) Fungsi etika dan moralitas, dan 5) Fungsi estetis. Kelima fungsi tersebut saling melengkapi dengan tidak terlalu menonjolkan salah satu fungsinya saja. Kesusastraan memiliki modal yang kuat untuk menanamkan nilai-nilai moralitas sesuai dengan falsafah bangsa. Agastia (1994: 2) menyatakan bahwa ada abad ke $X$, raja Dharmawangsa teguh menjadi pelindung suatu proyek besar yang dikenal dengan sebutan "mangjawaken byasamata" yang berarti membahasa jawakan ajaran-ajaran bhagawan Byasa.Ajaran-ajaran yang dimaksud tidak lain epos Mahabharata (asta dasa parwa), demikian pula kitab Ramayana karangan Maharsi Valmiki juga ikut diterjemahkan ke dalam bahasa Jawa. Kesusastraan Hindu mengalami perkembangan hingga runtuhnya Kerajaan Majapahit, dan susastra-susastra Hindu yang telah ada akhirnya diselamatkan di Bali. Di Bali sendiri, kesusastraan Hindu mendapat apresiasi yang tinggi, tidak hanya diselamatkan namun dikembangkan ke dalam berbagai bentuk. Kesusastraan Hindu yang paling populer di antaranya epos besar Ramayana dan Mahabharata yang hingga kini masih hidup di tengah-tengah masyarakat luas. Tidak hanya itu, susastra-susastra seperti, Sarasamuccaya, Slokantara, Canakya Nitisastra, Purana dan sejenisnya tetap memikat hati para pengamat sastra maupun agama Hindu khususnya. Dalam kesusastraan Hindu tidak hanya tertuang nilai religi semata, namun juga terkandung nilai etika, moralitas, pendidikan, filsafat hidup, dan sebagainya disamping nilai keindahan dalam hal struktur yang membangunnya. Atas dasar asumsi tersebut, kesusastraan Hindu dapat dikatakan memiliki kontribusi yang besar bagi pendidikan karakter karena kandungan ajarannya yang luas dan mendalam.

\section{PEMBAHASAN}

Kesusastraan Hindu merupakan salah satu aset agama Hindu yang sangat berharga karena 
di dalamnya terkandung banyak nilai tidak hanya tentang ketuhanan, namun juga tentang pedoman berprilaku, etika, moralitas, pendidikan. Hingga kini kesusastraan Hindu masih cukup digemari oleh para pemerhati seni sastra dan agama Hindu. Dalam pembahasan ini penulis membatasi kesusatraan Hindu yang akan dikaji terkait kontribusinya terhadap pendidikan karakter. Di antara sederetan kesusastraan Hindu, hampir seluruhnya mengandung unsur pendidikan, hanya saja tidak diungkapkan secara eksplisit oleh pengarangnya. Beberapa kutipan-kutiapan dalam susastra yang dapat dikaji dalam hal ini antara lain Ramayana, Mahabharata, Sarasamuccaya, Siva Purana, dan Canakya Niti Sastra, Secara rimgkas akan dibahas sebagai berikut.

\subsection{Sarasamuccaya}

Dalam kesusastraan Hindu, Sarasamuccaya memiliki kedudukan penting yakni sebagai kitab Smrti yang lebih banyak menguraikan tentang etika danmoralitas keagamaan yang bersifat praktis dan merakyat di lingkungan umat Hindu. Sarasamuccaya yang disusun oleh Bhagawan Wararuci merupakan intisari dari Astadasa Prawa Mahabharata. Ajaran moral yang terangkum dalam kitab ini memuat beberapa aspek kehidupan yakni1: 1) Empat tujuan hidup manusia (Catur Purusa Artha), 2) Nastika, Wak, Satya, Ahimsa, Astenya, Paradara, dan Susila, 3) Dana-punia, Anak, Orangtua, Guru dan ajaran Yama Niyama Brata, 4) Ajaran tentan Artha, Sukha, Tirta Yatra, Daridra dan Sangsarga, 5) Ajaran Dharma yang meliputi pengertian Dharma, keagungan Dharma, Sumber-sumber Dharma dan perbuatan-perbuatan Dharma, 6) Catur Warna dan ajaran Tri Kaya Parisudha, 7) Ajaran tentang Purwa Karma, Kematian, TuhaPati, Pitrayana, Dewa Yana dan Kebodohan, 8) Stri (Wanita), Raga Dwesa, Tresna (keterikatan), dan Moksah atau kebahagiaan yang abadi (Bantas dan Djelantik, 1992: 29).
Dalam salah satu aspek pada kitab ini, terdapat beberapa kutipan sloka tentang etika seoang anak terhadap guru rupaka (orangtua), dan guru pengajian (guru yang memberian ilmu pengetahuan tentang kebenaran, kesucian, serta memberikan pendidikan rohani). berikut beberapakutipan sloka tersebut:

Adalah orang yang begini prilakunya, tidak menjadikan ibu bapaknya tukang masak, iapun tidak makan jika tidak disuruh oleh ibu bapaknya, segala sesuatu yang dimakannya yang telah disisakan oleh ibu bapaknya, itulah dimakan olehnya setiap hari, maka orang yang demikian perbuatannya, adalah merasa diri senang puas, sebab memperoleh kebahagiaan yang tiada taranya kelak.

\section{Sarasamuccaya 227}

Sloka tersebut mengisyaratkan seorang anak untuk selalu hormat dan bhakti kepada ornagtuanya, selalumengutamakan pelayanan yang tulus kepada mereka sehingga nantinya akan mendapatkan kebahagiaan yang tiada taranya kelak. Selain itu anak juga diharapkan untuk memiliki rasa simpati kepada orang yang tertimpa musibah, membantu orang yang memerlukan seperti ornag miskin, orang sakit, seperti yang dipaparkan dalam sloka berikut

Yang dianggap anak adalah orang yang menjadi pelindung ornag yang memerlukan pertolongan serta untuk menolong kaum kerabat yang tertimpa kesengsaraan, segala hasil usahanya agar disedekahkan, gunanya ia memasak menyediakan makanan untuk orang-orang miskin, oran yang demikian itu putra sejati namanya.

\section{Sarassamuccaya 228}

Lebih lanjut terkait etika sebagai seorang anak ataupun sisya (murid) hendaknya memperhatikan sloka-sloka berikut: 
Jika ada orang berkhianat terhadap guru, terhadap ibu dan bapa, dengan jalan perbuatan, perkataan dan pikiran, orang yang demikian perilakunya amat besarlah dosanya, lebih besar daripada dosa bhrunaha artinya menggugurkan kandungan, singkatnya amat besarlah dosanya.

\section{Sarassamuccaya 234}

Yang patut dilakukan adalah sebagai berikut ini, jangan menjawab secara berolok-olok kepada guru, jika beliau gusar, berang hatinya, sabarkan beliau, hiburlah, usahakanlah segala yang menyenangkan beliau.

\section{Sarassamuccaya 237}

Dan lagi, jangan sekali-kali mencela guru, meskipun keliru perbuatan beliau, hendaklah diusahakan baik-baik cara perlakuan yang layak kepada guru, agar berhasil melaksanakan pengabdian kepada beliau, sangatlah menyebabkan usia pendek serta menimbulkan dosa jika menghina guru.

\section{Sarassamuccaya 238}

Perilaku anak terhadap orangtua hendakanya sebagai berikut: memberi salam selamat dan menyapanya dengan sopan santun, mempersilahkan duduk, kemudian menyembah serta dengan sopan duduk bersila dihadapannya, pada waktu berangkat hendaklah mengantarkannya.

\section{Sarassamuccaya 248}

Akan pahala horat bakti terhadap orangtua, adalah empat jenis hal yang bertambah, perinciannya : kirti, ayusa, bala, yaca. Kirti artinya pujian tentang kebaikan, ayusa artinya hal hidup, bala artinya kekuatan, yaca artinya peninggalan yang baik (jasa), itulah yang bertambah sempurna sebagai pahala hormat bakti terhadap orangtua.

\section{Sarassamuccaya 250}

Demikian secara ringkas disampaikan kutipan sloka dalam sarasamuccaya terkait etika sebagai seorang anak, maupun murid yang sejalan dengan fungsi pendidikan untuk membentuk kepribadian anak yang berbudi pekerti luhur.

\subsection{Canakya Nitisastra}

Canakya Nitisastra merupakan sebuah pustaka yang berisi pemikiran-pemikiran tinggi tentang moralitas, pergaulan sehari-hari dan juga bhakti kepada Tuhan Yang Maha Esa (Sri Hari (dalam Darmayasa, 1995: xvii). Berbicara tentang pendidikan karakter, dalam Canakya Nitisastra cenderung mengedepankan peran orangtua sebagai pendidik anak dalam lingkungan keluarga, serta anak yang diharapkan nantinya adalahyang berbudi pekerti luhur yang diibaratkan seperti pohon cendana di tengah hutan. Berikut kutipan-kutipan Sloka dalam Canakya Nitisastra terkait masalah pendidikan karakter:

Orang bijaksana hendaknya mengajarkan putranya tata susila, pengetahuan Niti Sastra dan ilmu pengetahuan suci lainny, sebab seorang putra yang mahir dalam pengetahuan Niti Sastra dan pengetahuan suci lainnya akan menyebabkan keluarga terpuji.

Canakya Nitisastra II.10

Seorang bapak danibu yang tidak memberikan pelajaran (kesucian) kepada anaknya, mereka berdua adalah musuh dari anak tersebut. Anak tersebut tidak akan ada artinya di masyarakat, bagaikan seekor burung bangau di tengah-tengah kumpulan burung angsa. 
Canakya Nitisastra II.11 Anak yang dididik dengan memanjakan akan menjadi durhaka dan jahat. Sedangkan dengan memberikan hukuman-hukuman ia akan menjadi baik. oleh karena itu didiklah putraputri dan murid-murid anda dengan cara memberikan hukuman-hukuman dan tidak dengan cara memanjakannya.

Canakya Nitisastra II.12

Hukuman-hukuman yangdimakud dalam sloka ini bukanlah hukumuan berupa siksaan ataukekerasan verbal maupunfisik, namunlebih kepada mendidik anak melalui disiplin yang kuat,. Lebih lanjut disampaikan karakter anak yang diharapkan dari sebuah keluarga seperti kutipan sloka berikut:

Seluruh hutan menjadi wangi hanya karena ada sebuah pohon dengan bunga indah dan harum semerbak. Begitu juga halnya kalau di dalam keluarga terdapat seorang anak yang suputra.

Canakya Nitisastra III.14

Seluruh hutan terbakar hangus hanya karena satu pohon kering yang terbakar.

Begitulah seorang anak yang kuputra menghancurkan dan memberikan aib bagi seluruh keluarga.

Canakya Nitisastra III.15 Asuhlah putra dengan cara memanjakannya sampai berumur lima tahun, memberikan hukuman-hukuman selam sepuluh tahun berikutnya. Kalau ia sudah menginjak umur enam belas tahun didiklah ia dengan cara berteman.

Canakya Nitisastra III.18

Nampaknya sloka III.18 tersebut bertentangan dengan sloka II.12 yang mengatakan bahwa anak yang dididik dengan cara dimanja akan menjadi akan durhaka, sedangkan menurut sloka III.18 bahwa anak diasuh dengan cara memanjakannya hingga berumur 5 tahun. Menurut pandangan penulis, maksud dari kata memanjakan anak hingga berumur lima tahun hendaknya diartikan sebagai pemberian kasih sayang oleh orang tua dengan catatan tidak terlalu berlebihan, kemudian barulah anak dilatih untuk menumbuhkan kesadaran dan disiplinnya selama sepuluh tahun berikutnya, bukanlah dengan memberikan hukuman secara verbal maupun fisik, melainkan dengan mendidik agar anak tumbuh menjadi anak yang disiplin, memiliki tanggung jawab, bertata susila, memahami etikanya sebagai anak mauapun murid nantinya serta berbudi pekerti yang luhur. Mendidik anak bisa dimulai dengan membiasakan mereka bangun pagi, membersihakn kamar tidurnya sendiri, mencuci perabotan makannya sendiri, mencuci pakaiannya, membiasakan anak Tri Sandhya tiga kali sehari, mengucapkan salam kepada orang tua atau kepada tamu maupun teman, berbicara sopan kepada orang tua maupun kerabat yang lebih tua. Dengan cara-cara sederhana tersebut akan melatih tanggung jawab, disiplin, dan etika anak sehingga tujuan dari pendidikan yaitu membentuk kepribadian anak yang luhur niscaya akan terwujud. Dari beberapa kutipan sloka tersebut di atas, maka dapat dikatakan bahwa kesusastraan Hindu memegang peranan penting di dalam pendidikan karakter, karena sloka-sloka tersebut memiliki makna yang cukup luas yang dapat dikembangkan lebih lanjut. Beberapa kutipan sloka tersebut tentu belum dapat mewakili kesusastraan Hindu yang jumlahnya cukup banyak, namun hal terpenting yang dapat dilakukan adalah upaya untuk mentradisikan ajaran-ajaran dalam kesusastraan tersebut sehingga menjadi sebuah kebiasaan dan tertanam di benak anak. Dalam salah satu sloka Canakya Nitisastra disampaikan sebagai berikut: 
Isilah waktu setiap hari dengan menghafalkan satu sloka 1 ayat, atau setengah sloka, atau seperempat sloka ataupun satu huruf dari sloka tersebut. Atau isilah hati-hari anda dengan bersedekah, belajar kitab-kitab suci dan kegiatan bermanfaat lainnya. Dengan demikian hari-hari anda akan menjadi berarti.

\section{Canakya Nitisastra II.13}

\section{PENUTUP}

Susastra Hindu dalam hal ini Sarasa- muccaya, dan Canakya Nitisastra lebih daripada itu memiliki peran penting dalam kehidupan beragama Hindu. Tidak hanya itu, Susastra Hindu tersebut juga memiliki fungsi pendidikan yang kental, etika, moralitas dan segudang nilai kebajikan lainnya. Baik Sarasamuccaya maupun Canakya NItisastra dapat dikatakan memiliki relevansi dengan pendidikan karakter yang tengah digalakkan pemerintah dewasa ini. Keduanya mengandung ajaran-ajaran kebaikan yang dapat dijadikan sebagai pedoman dalam menjalani kehidupan yang lebih baik. Peran orang tua, guru, tokoh masyarakat sangat penting dalam hal mentransmisi, mentradisikan nilai-nilai dalam kesusastraan tersebut, terlebih menjadi teladan bagi anak. Nilai yang terkandung dalam karya sastra tersebut hendaknya dapat dipahami, dan terpenting diimplementasikan dalam praktek kehidupan keluarga, maupun masyarakat sehingga apa yang menjadi tujuan pendidikan secara umum maupun tujuan pendidikan agama yakni terbentuknya karakter yang baik dapat terwujud. 


\section{DAFTAR RUJUKAN}

Agastia, IBG. 1994. Kesusastraan Hindu Indonesia (Sebuah Pengantar). Denpasar: Yayasan DharmaSastra.

Darmayasa, I Made.1995. Canakya Nitisastra. Denpasar: Yayasan Dharma Naradha

Bantas, I Ketut dan Gde Ketut Djelantik. 1992. Materi Pokok Sarasamuccaya. Jakarta: Direktorat Jenderal Bimbingan Masyarakat Hindu danBuddha dan Universitas Terbuka

Cholisin. 2011. Peran Guru PKn dalam Pendidikan Karakter. Makalah (tidak diterbitkan) FKIP UAD Yogyakarta.

Jalaluddin, dan Abdullah Idi. 2012. Filsafat Pendidikan, Manusia, Filsafat, dan Pendidikan. Jakarta: PT. Rajagrafindo Persada.

Kajeng, I Nyoman, dkk. 1997. Sarasa- muccaya, Surabaya, Paramita.

Lickona, Thomas. 2013. Pendidikan Karakter Panduan Lengkap Mendidik Siswa Menjadi Pintar dan Baik.Bandung: Nusamedia.

Nurkancana, Wayan. 2010. Keutamaan Mahabharata. Denpasar: Pustaka Manikgeni.

Titib, I Made. 2011. Bahan Ajar Itihasa (Viracarita) Ramayana \& Mahabharata Kajian Kritis SumberAjaran Hindu. IHDN Denpasar. 